\title{
Factors influencing strategic alliance outcomes in a manufacturing supply chain: role of alliance motives, interdependence, asset specificity and relational capital
}

\begin{abstract}
Integration of various theories is essential to completely understand and explain strategic alliances in a supply chain. The purpose of this paper is to develop a framework by integrating the features of transaction cost theory, resource-based theory, contingency theory, social exchange theory, and Kelley's personal relationship theory and test the framework through empirical research. The present study addresses the impact of strategic alliance motives, environment, asset specificity, perception of opportunistic behavior, interdependence between supply chain partners, and relational capital on strategic alliance outcomes. Besides, the study has also tested the role of relational capital as a central mediating construct. A sample of 2156 companies representing different industries in manufacturing in Malaysia was selected for the distribution of questionnaire. We tested the structural model using structural equation modeling (SEM). Based on the results, we conclude the following significant relationships: (1) strategic alliance motives and perception of opportunistic behavior on interdependence and relational capital, (2) interdependence on relational capital, (3) environment on strategic alliance motives, (4) relational capital on strategic alliance outcomes, and (4) the mediating role of relational capital. The current study adds significantly to the body of knowledge on strategic alliances and can help managers identify factors that influence the success of strategic alliances and provide a proper direction to develop robust and effective collaborative relationships between supply chain partners.
\end{abstract}

Keyword: Strategic alliance; Life cycle; Integrated framework; Manufacturing supply chain; Malaysia 